\title{
A Vivência Materna do Processo de Separação-Individuação de Bebês que Frequentavam ou Não a Creche
}

\author{
Tatiele Jacques Bossi ${ }^{*}, 1$ \\ Orcid.org/0000-0003-0487-8112 \\ Cesar Augusto Piccinini ${ }^{1}$ \\ Orcid.org/0000-0002-4313-3247
}

${ }^{1}$ Universidade Federal do Rio Grande do Sul, Porto Alegre, RS, Brasil

\begin{abstract}
Resumo
Este estudo investigou a vivência materna do processo de separação-individuação mãe-bebê no primeiro ano de vida. Em particular, buscou investigar, a partir do relato materno, as particularidades desse processo quando o bebê frequenta ou não a creche. Foi realizado um estudo de caso múltiplo envolvendo seis mães e seus bebês, entre os quais três frequentavam a creche e três não frequentavam. As mães foram entrevistadas no $6^{\circ}$ e $12^{\circ}$ mês de vida dos bebês. A análise de conteúdo qualitativa dos relatos maternos revelou que os bebês vivenciavam o processo de separação-individuação conforme preconizado por Mahler, Pine e Bergman (1975/1977), independentemente de frequentarem ou não a creche. Contudo, a análise apontou diferenças nos relatos das mães quanto aos seus sentimentos relacionados a se separar dos filhos, sendo que revelaram mais sofrimento entre aquelas cujos bebês não frequentavam a creche. Os resultados sugerem que o processo de separação-individuação mãe-bebê se constituiu em um fenômeno intrapsíquico importante, tanto para o bebê como para a mãe, e foi ocorrendo como o esperado, entre os casos investigados, independentemente do bebê frequentar ou não a creche.
\end{abstract}

Palavras-chave: Creche, processo de separação-individuação, desenvolvimento emocional.

\section{Maternal Experience of the Separation-Individuation Process in Infants who Attended or Did Not Attend Daycare}

\begin{abstract}
This study investigated the maternal experience of the separation-individuation process in the first year of life. In particular, it aimed to investigate the particularities of this process when the infant attends or does not attend daycare, based on reports of the mothers. A multiple case study was conducted involving six mothers and their infants, among whom three attended daycare and three did not. The mothers were interviewed when their children were 6 and 12 months of age. The qualitative content analysis
\end{abstract}

* Endereço para correspondência: Universidade Federal do Rio Grande do Sul, Instituto de Psicologia, Departamento de Psicologia do Desenvolvimento e da Personalidade, Rua Ramiro Barcelos, 2600/111, Bom Fim, Porto Alegre, RS, Brasil 90035003. Fone: (51) 3316-5246; Fax: (51) 3316-5473. E-mail: tatielejbossi@, gmail.com e piccinini@portoweb.com.br 
of the maternal reports revealed that the infants experienced the separation-individuation process, as described by Mahler, Pine, and Bergman (1975/1977), regardless of whether they attended daycare or not. The mothers reported differences in the feelings regarding their separation from the child, which revealed more suffering among those whose infants did not attend daycare. The results suggested that the separation-individuation process is an important intrapsychic phenomenon, both for the infant and for the mother, and was occurring as expected in the cases investigated, regardless of whether the infant attended daycare or not.

Keywords: Child daycare, separation-individuation process, emotional development.

\section{La Experiencia Materna del Proceso de Separación-Individualización en Bebés que Asisten a lo Jardin Infantil o No}

\section{Resumen}

Este estudio investigo la experiencia materna del proceso de separación-individuación madre-hijo en el primer año de vida. En particular, se trató de investigar, desde la cuenta de la madre, las peculiaridades de este proceso cuando el bebé asiste a la guardería o no. Fue realizado un estudio de casos múltiples em que participan 6 madres y sus bebés, incluyendo 3 en guarderías y 3 no. Las madres fueron entrevistadas a los 6 y 12 meses de edad de los bebés. El análisis de contenido cualitativo de los informes maternos reveló que los bebés han demostrado que responden al proceso de separación-individuación según lo recomendado por Mahler, Pine y Bergman (1975/1977), independientemente o no de asistir al jardín infantil. Sin embargo, el análisis mostró diferencias en las cuentas de las madres sobre sus sentimientos relacionados con separar a los niños, y reveló más sufrimiento entre aquellos cuyos bebés no estaban asistiendo al jardín infantil. Los resultados sugieren que el proceso de separación-individuación se convirtió en un fenómeno intra-psíquico importante, tanto para el bebé como para la madre, y estaba sucediendo como era de esperar, entre los casos investigados, independientemente de el bebé asistir o no al jardín infantil.

Palabras clave: Jardín infantil, proceso de separación-individuación, desarrollo emocional.

O processo de separação-individuação ( $1^{\text {a }}$ individuação) descrito por Mahler et al. (1975/1977) refere-se a um fenômeno intrapsíquico que ocorre entre os 4 e 36 meses de vida da criança, e abrange dois aspectos: a separação, que se refere à saída da criança da fusão simbiótica com a mãe; e a individuação, que implica em aquisições psíquicas que permitem à criança assumir suas próprias características. No ápice da simbiose mãe-bebê começaria esse processo descrito em quatro subfases: diferenciação (4 a 9 meses), exploração (10 a 16 meses), reaproximação (17 a 24 meses), e consolidação da individuação ( 25 a 36 meses). Tendo em vista a idade dos bebês acompanhados no presente estudo ( 6 a 12 meses), serão destacadas as duas primeiras subfases como indicadores da separação-indivi- duação.

A subfase de diferenciação tem início por volta do quarto mês de vida do bebê, que passa a manter-se mais alerta durante os períodos de vigília, o que o permite dirigir-se ao mundo externo. Essa subfase se caracteriza pela diminuição, por parte do bebê, da dependência corporal da mãe, que até então era total. A firmeza de tronco possibilita a ele distanciar-se corporalmente da mãe e, assim, reconhecê-la tátil e visualmente como uma parceira na simbiose, e não como parte de seu corpo. Conforme Mahler et al. (1975/1977), o bebê, ao admirar-se com as características do rosto da mãe, passa a compará-lo com a face de outros adultos. Se a simbiose ocorrer adequadamente e a criança desenvolver o sentimento de confiança básica, volta-se com 
maior curiosidade para o exame dos estranhos. Do contrário, o exame de outros adultos pode se transformar em ansiedade aguda com relação a estranhos.

Já a segunda subfase, denominada exploração, tem início por volta dos 10 meses do bebê e se justapõe à subfase anterior. Ocorre uma expansão das capacidades motoras do bebê e, consequentemente, aumenta a exploração do ambiente ao seu redor. Segundo Mahler et al. (1975/1977), essa subfase se caracteriza pelo envolvimento narcisista do bebê em suas próprias habilidades, em seu corpo e na investigação do ambiente ao seu redor. Isso possibilita a ele o que se chama de impermeabilidade à frustração, tornando-o mais tolerante a batidas, a quedas e a outras frustrações que venha a sofrer. Devido ao investimento narcisista, o bebê aventura-se para mais longe da mãe e fica longo período absorto em suas atividades. No entanto, de tempos em tempos, retorna a ela para receber o reabastecimento emocional, adquirido através do contato físico com a mãe. A locomoção indica o final do rompimento da unidade simbiótica mãe-bebê, estabelecida nos primeiros meses de vida, o que representaria o nascimento psicológico da criança. Este se refere à capacidade do bebê de tornar-se uma pessoa separada da mãe, ao adquirir o início da identidade do self (Mahler, 1979/1982).

Cabe ressaltar que a separação-individuação é uma importante conquista do desenvolvimento infantil, mas está relacionada ao desenvolvimento da própria mãe. Tornar-se mãe também envolve passar por um processo de separação-individuação, denominado terceira individuação (Colarusso, 1990), considerada como um processo contínuo de elaboração do self e de diferenciação objetal que ocorre na idade adulta. $\mathrm{O}$ adulto jovem em processo de transição para a terceira individuação é considerado como intrapsiquicamente sozinho, cortado de seus apegos infantis, mas sem ter estabelecido uma relação de tamanha intensidade com um eventual substituto dos objetos infantis, como cônjuge e filhos. Segundo Colarusso (1990), a partir do processo de desenvolvimento, esse isolamento normal do adulto jovem que preenche o vazio da separação real ou intrapsíquica dos objetos in- fantis, se dirige para o estabelecimento do papel parental, que se constitui como questão central da terceira individuação. Como ressaltado por Colarusso (1990), aspectos do processo de separação-individuação infantil são reeditados em diversos momentos ao longo do ciclo vital, como por exemplo, na relação com os próprios pais na adolescência e início da idade adulta (Aslan, 2013; Kins, Soenens, \& Beyers, 2011; Koepke \& Denissen, 2012) e com o filho no momento que se constitui a parentalidade (Bellini, 2008; Diamond, Heinicke, \& Muntz, 1996).

Pode-se ressaltar, portanto, que o processo de separação-individuação dos filhos descrito por Mahler et al. (1975/1977) traz implicações para a individuação dos próprios pais, e em especial para a mãe, que também foi foco do presente estudo. Conforme Colarusso (1990), há uma ressignificação da relação que os novos pais estabeleciam e estabelecem com os seus próprios pais, bem como o retorno psíquico dos resquícios de seu processo de separação-individuação infantil. Tais aspectos sugerem que a separação-individuação mãe-bebê é complexa, por envolver não só o mundo psíquico do bebê, mas também o de sua mãe.

Retomando os aspectos preconizados por Mahler et al. (1975/1977), é relevante destacar que a teoria do processo de separação-individuação se refere ao contexto de cuidados maternos dispensados aos bebês. Os autores não estudaram outras formas de cuidado, em especial a creche, a fim de investigar possíveis particularidades no processo de separação-individuação associados ao fato do bebê permanecer muitas horas diárias distante da mãe, em um ambiente de cuidado coletivo, realizado por diferentes educadoras.

$\mathrm{Na}$ verdade, são raros os estudos nacionais e internacionais publicados sobre o tema entre 2005 a 2017, com base na teoria de Mahler et al. (1975/1977), conforme levantamento realizado nas bases de dados SciELO, PsycINFO e PubMed. Alguns tendem a focar na transição para a maternidade e paternidade, concomitante à segunda individuação, que ocorre na adolescência; ou então associado à terceira individuação, que exige uma identidade adulta estruturada a fim de a mulher e o homem poderem vivenciar 
a parentalidade (Kins, Soenens, \& Beyers, 2012; Koepke \& Denissen, 2012; Meeus, Iedema, Maassen, \& Engels, 2005). No entanto, poucos investigaram aspectos da primeira individuação (do bebê) e sua concomitância com a terceira individuação (da mãe), de modo a entender essa vivência mútua, foco do presente estudo.

Entre estes, encontram-se estudos que investigaram o processo de separação-individuação, quando o bebê frequentou a creche. Por exemplo, estudo de Bossi, Soares, Lopes e Piccinini (2014) teve como objetivo investigar a adaptação de 13 bebês à creche durante as subfases do processo de separação-individuação, a saber, diferenciação (4 a 7 meses), exploração (10 a 15 meses) e reaproximação (19 a 21 meses). As mães e pais de Porto Alegre (RS) responderam a entrevistas sobre o período de adaptação do bebê à creche. Os dados revelaram que diferentes reações dos bebês (choro, adoecimento, recusa em se alimentar) e sentimentos parentais (insegurança, desconfiança, tranquilidade) se fizeram presentes nas três subfases investigadas. Dependendo do contexto, essas reações e sentimentos contribuíram tanto para incentivar, como para dificultar ou impedir a adaptação do bebê à creche. Os resultados revelaram que, independentemente da subfase investigada, quanto mais seguros e satisfeitos os pais estavam com relação à adaptação, mais eles conseguiam oferecer apoio emocional para o bebê. Isso possibilitou, de certa forma, que a creche se tornasse uma referência para a criança e permitiu o seguimento do seu processo de separação-individuação, mesmo distante da mãe.

Bellini (2008) também investigou a vivência materna do processo de separação-individuação, acompanhando quatro mães de Porto Alegre (RS), desde o primeiro ano de vida, até antes da entrada do bebê na educação infantil, no segundo ano de vida. Os resultados revelaram que, até o final do primeiro ano do bebê, as mães manifestavam o desejo de retomarem um espaço próprio e mais independente, como se a crescente individuação do bebê impulsionasse a mãe para o resgate da sua individualidade. Isso permitiu, inclusive, que as mães tomassem a decisão de colocar os bebês na creche.
Dessa forma, pode-se ressaltar que, ao longo do processo de desenvolvimento, tanto os bebês como as próprias mães vão adquirindo capacidade psíquica para se separarem e individuarem. Isto também é destacado no estudo realizado por Lopes et al. (2007) que teve por objetivo investigar os sentimentos maternos em relação ao desenvolvimento dos filhos, especialmente às novas aquisições infantis aos 12 meses de idade. As 28 mães que foram entrevistadas revelaram que, à medida que o bebê se desenvolvia em sua independência, elas também desejavam que os filhos ficassem mais livres e estimulavam os seus comportamentos de afastamento. Isso mostra um bebê que busca a sua individuação com relação à mãe, e uma mãe que incentiva esse movimento por parte dele.

Cabe mencionar, também, que a crescente procura por creches coloca a importância de se investigar aspectos referentes ao processo de separação-individuação nesse contexto. Segundo o Censo escolar da educação básica (Instituto Nacional de Estudos e Pesquisas Educacionais Anísio Teixeira [INEP], 2014), entre os anos de 2007 a 2013 ocorreu um crescimento no número de matrículas em creches no Brasil na ordem de $42 \%$. De acordo com o Observatório do Plano Nacional da Educação - PNE (2016) 29,6\% das crianças de 0 a 3 anos estavam matriculadas em creches no ano de 2014. E a meta é de que, até o ano $2024,50 \%$ das crianças nessa faixa etária tenham acesso à educação infantil.

Considerando o exposto, o objetivo deste estudo foi investigar a vivência materna do processo de separação-individuação mãe-bebê no primeiro ano de vida. Em particular, buscou investigar, a partir do relato materno, as possíveis particularidades desse processo quando o bebê frequenta ou não a creche.

\section{Método}

\section{Participantes}

Participaram do estudo três díades mãe-bebê cujos bebês frequentavam a creche em período integral (oito a dez horas diárias) e três díades mãe-bebê cujos bebês não frequentavam a creche e ficavam, prioritariamente, sob os cuidados 
maternos. No início do estudo, os bebês tinham 6 meses e, no final, 12 meses de idade, período que corresponde às subfases de diferenciação e exploração do processo de separação-individuação (Mahler et al., 1975/1977). As mães (26 a 41 anos) tinham ensino superior incompleto à pós-graduação, eram primíparas e residiam com o pai do bebê. A creche frequentada por três dos bebês atendia funcionários de uma universidade federal e na avaliação da Infant/Toddler Environment Rating Scale -ITERS-R (Harms, Cryer, \& Clifford, 2003), recebeu critério "bom", o que indica que atendia ao que se espera para o desenvolvimento da criança.

As díades participantes foram selecionadas entre as integrantes do projeto "Impacto da creche no desenvolvimento socioemocional e cognitivo infantil: estudo longitudinal do sexto mês de vida do bebê ao final dos anos pré-escolares - CRESCI" (Piccinini, Becker, Martins, Lopes \& Sperb, 2011) que tem como objetivo investigar o impacto da creche no desenvolvimento socioemocional e cognitivo de crianças, desde seu sexto mês até o final dos anos pré-escolares. O projeto foi aprovado pelo Comitê de Ética da Universidade Federal do Rio Grande do Sul (UFRGS) e as participantes assinaram o Termo de Consentimento Livre e Esclarecido. Para fins do presente estudo, foram selecionadas do Projeto CRESCI, as primeiras seis díades entrevistadas pela primeira autora deste artigo.

\section{Delineamento, Procedimento e Instrumentos}

Utilizou-se o delineamento de estudo de caso múltiplo (Stake, 2006), de caráter longitudinal, com o objetivo de investigar a vivência materna do processo de separação-individuação mãe-bebê no primeiro ano de vida, e as particularidades desse processo quando o bebê frequentava ou não a creche. Para fins deste estudo, foram consideradas as duas fases iniciais de coletas de dados do Projeto CRESCI, aos 6 e 12 meses de idade dos bebês. Vários instrumentos de coleta de dados foram usados em cada fase, mas serão aqui destacados apenas aqueles que foram utilizados para responder ao objetivo do presente estudo.

Seguindo as etapas do Projeto CRESCI, as mães foram contatadas via telefone e/ou e-mail e foram convidadas a participar do estudo. Foi agendado um primeiro encontro para a assinatura do Termo de Consentimento Livre e Esclarecido por parte da mãe e o preenchimento da Ficha de Dados Demográficos da Família (Núcleo de Infância e Família/Projeto CRESCI [NUDIF/ CRESCI], 2011a). Trata-se de uma ficha estruturada composta por questões sobre dados demográficos da mãe e do pai do bebê tais como idade, escolaridade, dentre outros; assim como sobre o bebê, como idade gestacional ao nascimento e peso ao nascer.

Em seguida, foi realizado um segundo encontro para que elas respondessem a duas entrevistas: Entrevista sobre a experiência da maternidade $-6^{\circ}$ mês (NUDIF/CRESCI, 2011b): composta por blocos de questões que abordam, por exemplo, a experiência da maternidade e a decisão de colocar (ou não) o bebê na creche (ex: Como tu estás te sentindo como mãe? Porque vocês escolheram colocar (ou não) o bebê na creche?); e a Entrevista sobre momentos de separações mãe-bebê - $6^{\circ}$ mês (NUDIF/CRESCI, 2011c): composta por blocos de questões que abordam as experiências de separações entre a mãe e o bebê aos 6 meses, baseados nos conceitos de Mahler et al. (1975/1977; ex. Como é para ti deixá-lo(a) com outras pessoas? Como o bebê reage nesses momentos de separações? Como você se sente e reage?). Para as mães cujos bebês frequentavam a creche, foi realizada a Entrevista sobre a adaptação do bebê à creche (NUDIF/ CRESCI, 2011d), um mês após a entrada na creche, composta por blocos de questões que investigam o período de adaptação e seus efeitos no bebê e na família (ex., Como foram os primeiros dias do bebê na creche? Como está a adaptação? Como ele(a) tem interagido contigo depois que entrou na creche?).

Na fase seguinte, aos 12 meses dos bebês, as mães responderam a versões adaptadas das duas entrevistas aplicadas na fase anterior (NUDIF/ CRESCI, 2011e, 2011f). Todas as entrevistas 
eram estruturadas, aplicadas de forma semidirigida, individualmente no local de preferência das participantes. Elas tiveram duração média de 60 minutos, foram gravadas e transcritas.

\section{Resultados}

Os dados foram submetidos à análise de conteúdo qualitativa (Laville \& Dionne, 1999) com o objetivo de investigar: (1) a vivência materna do processo de separação-individuação mãe-bebê no primeiro ano de vida; e, (2) as particularidades desse processo quando o bebê frequenta ou não a creche. Foram consideradas duas categorias de análise que representam as subfases do processo de separação-individuação (Mahler et al., 1975/1977): (a) Separação-individuação e subfase de diferenciação ( $6^{\circ}$ mês), que se refere à primeira subfase; e, (b) Separação-individuação e subfase de exploração ( $12^{\circ}$ mês), que se refere à segunda subfase. Em cada categoria foram destacados os relatos sobre a experiência da maternidade e os aspectos relacionados ao desenvolvimento emocional dos bebês, em cada faixa etária. Para os três bebês que frequentavam a creche, também se examinou a adaptação e a experiência na creche. Apresentam-se, a seguir, os principais achados dos três casos de bebês que frequentavam a creche, seguidos pelos três casos de bebês que não frequentavam a creche. Os nomes utilizados para representar as mães e os bebês são fictícios.

\section{Caso 1: Martha (mãe) e Vinícius (frequentava a creche)}

Separação-individuação e subfase de diferenciação ( $6^{\circ}$ mês). Com relação à experiência da maternidade, Martha definiu-se como uma mãe "atenciosa", "responsável", "amoro$s a$ " e que estimulava a independência do filho. Ela ainda ressaltou que se tornar mãe lhe proporcionou "um objetivo maior na vida". Outro aspecto ressaltado foi o fato de gostar de estar com o filho e ver os progressos de seu desenvolvimento, mas também o desejo de retomar sua rotina no trabalho: "Ao mesmo tempo que eu gosto de estar com ele, eu sinto falta do trabalho". Já com relação ao desenvolvimen- to emocional do filho, Martha ressaltou a sua percepção de que o Vinícius era capaz de manifestar satisfação frente às brincadeiras e insatisfação quando percebia não estar recebendo atenção da mãe: "Ele não gosta quando ele fica muito tempo sem atenção, . . ele começa a fazer uma cara de sério e a bater as pernas". Ela também mencionou que percebia Vinícius como muito curioso, já que ele interagia com o que estava ao seu alcance. Com relação à adaptação à creche, Martha destacou que não se sentiu culpada por inserir o filho na creche, já que ela sabia que, nesse contexto, ele estaria sendo cuidado e estimulado no seu desenvolvimento: "Eu não me sinto culpada... porque eu acho que vai ser um ambiente bom ali pra ele". Ela ressaltou que o manejo das educadoras durante a adaptação permitiu que ela não percebesse, em Vinícius, comportamentos de estranhamento de forma acentuada. Desse modo, Martha ficou disponível na creche durante o período de adaptação, mas não precisou ser solicitada: "Elas [educadoras] não são agitadas, conversam na linguagem deles, fazem brincadeiras, $e$ isso ajudou bastante o processo". Ela destacou que, após um mês na creche, percebia que o filho estava bem adaptado. Isso foi identificado através de comportamentos, como ir ao colo das educadoras quando chegava à creche e não demonstrar ansiedade para ir embora quando Martha chegava para buscá-lo.

Separação-Individuação e subfase de exploração (120 mês). Com relação à experiência da maternidade, Martha definiu-se como uma mãe preocupada com a segurança e o desenvolvimento do filho, mas ao mesmo tempo "light", no sentido de não se preocupar em demasia quando ele ficava doente ou a desafiava nos momentos em que ela dizia "não". Os momentos de reação de Vinícius ao "não" foram ressaltados por Martha como um desafio à maternidade, já que colocava a ela a necessidade de impor limites ao filho, sem intimidá-lo: "Então a mãe ter paciência e saber orientar para dizer não pra que a criança aprenda a ter um limite sem ter medo. Eu acho uma das coisas mais dificeis de ser mãe é como orientar a criança". Com relação ao desenvolvimento emocional do filho, 
Martha mencionou que percebia Vinícius mais dependente dela do que aos 6 meses de idade, pois exigia atenção de maneira constante. Ela destacou a expectativa de que desenvolvimentos na locomoção e alimentação fariam o filho exigir menos da sua parte. No entanto, ao ser questionada se ele realizava atividades sem precisar de ajuda (ex. pegar o brinquedo preferido), Martha mencionou resposta positiva e ressaltou o prazer do filho em realizar tais atividades: "Ele pode tirar, por exemplo, lá um livro ou uma peça de roupa dele e fica bem faceiro". Ela também mencionou o comportamento de Vinícius frente a lugares e pessoas estranhos e destacou sua capacidade de exploração, apesar de percebê-lo com um jeito mais "tímido e reservado". Com relação às eventuais e pequenas frustrações que Vinícius sofria ao explorar o ambiente (ex. uma queda), Martha destacou que ele tendia a manifestar desagrado, mas era facilmente acalmado e seguia em sua exploração. Ainda com relação às brincadeiras, Martha destacou que percebia, por vezes, que Vinícius necessitava retornar até ela, seja indo ao seu encontro ou the alcançando algum brinquedo: "Ele retorna, vê onde a gente está. Às vezes, pega e alcança um brinquedo pra gente, dai pra dizer que a gente tem que brincar com ele". Já referente à experiência do bebê na creche, Martha destacou que Vinícius permanecia cerca de 10 horas diárias na creche, durante quatro dias por semana. Ela avaliou de maneira positiva a escola que o filho frequentava, ao destacar o bom atendimento prestado às crianças. Além disso, ela ressaltou a comunicação adequada estabelecida com as educadoras, no sentido de receber informações sobre o dia do filho com elas: "Converso ali com elas, a gente chega lá e pergunta como é que foi a alimentação dele, como é que foi o dia".

A análise conjunta dos relatos maternos indica a vivência da maternidade marcada pelo prazer em estar com o filho e, ao mesmo tempo, o desejo de retornar ao trabalho, o que colocava a necessidade de um maior distanciamento entre mãe e bebê. Ao logo do período investigado, Martha passou a enfrentar outras preocupações, estimulada pelo próprio desenvolvimento do filho, como a necessidade de impor limites. Os re- latos associados ao filho denotam comportamentos que indicam a percepção materna de vivência satisfatória do processo de separação-individuação no primeiro ano de vida, como a curiosidade em explorar o ambiente ao redor, o prazer em realizar atividades de forma mais independente e a tolerância a pequenas frustrações ao longo do processo de desenvolvimento. Por fim, com relação à entrada e à experiência de Vinícius na creche, predominaram relatos que destacavam esse ambiente como adequado para o filho e a boa comunicação com as educadoras. Isso pareceu contribuir para a vivência satisfatória da mãe e do filho na creche.

\section{Caso 2: Lygia (mãe) e Érico (frequentava a creche)}

Separação-individuação e subfase de diferenciação ( $6^{\circ}$ mês). Com relação à experiência da maternidade, Lygia mencionou que não imaginava que essa experiência fosse tão satisfatória e ressaltou que estava se sentindo "completamente realizada". Ela definiu-se como uma mãe "muito boa" e destacou a relação positiva com a própria genitora: " $A$ minha mãe já passou tanta coisa boa pra gente, criou a gente tão bem. Então eu queria também passar". Com relação ao desenvolvimento emocional do filho, Lygia destacou aspectos pessoais dele, percebidos por ela, que se apresentaram como favoráveis para a relação satisfatória entre mãe e bebê, como ele ser calmo, sorridente e que interagia com os pais. Também foi destacado que Érico já atendia quando chamado pelo nome e que, há poucos dias, havia começado a sentar sem apoios. Com relação aos comportamentos frente a lugares e pessoas estranhos, Lygia destacou a percepção de que o filho não manifestava estranhamento, mas que ele ficava observando o ambiente para, posteriormente, seguir com seu padrão de interação: "Ele não estranha, mas ele fica olhando tudo, olhando pra ir reconhecendo o ambiente, ai depois age normal". Já referente à adaptação do filho à creche, Lygia mencionou que sentia um "aperto no peito" por não saber como ele iria reagir nos primeiros dias. No entanto, a adaptação de Érico ocorreu a partir de horários reduzidos nos 
primeiros momentos e Lygia precisou ficar disponível na creche apenas no primeiro dia. Essa adaptação, que ocorreu durante o primeiro mês na instituição, foi percebida por Lygia como satisfatória, já que Érico manifestava felicidade quando era levado à creche: "Hoje já pego ele e vou para a escolinha e ele faz festa, balança os pés, balança as mãos e vamos sair".

Separação-individuação e subfase de exploração $\left(\mathbf{1 2}^{\circ}\right.$ mês $)$. Com relação à experiência da maternidade, Lygia ressaltou que o modo como percebia o desenvolvimento adequado do filho para sua idade era algo que indicava que ela conseguia exercer, satisfatoriamente, o papel materno: "Ah, eu acho que eu tento fazer o possivel, eu acredito estar me saindo bem, até pelo desenvolvimento dele. A gente tem retorno, vendo que ele está bem". Já referente ao desenvolvimento emocional do filho, Lygia destacou que percebia comportamentos mais independentes por parte dele, sendo que o definiu como "um arteiro dentro de casa". Ela mencionou que Érico demonstrava prazer nessas atividades que realizava de forma independente e que ela o estimulava em suas conquistas. Com relação às eventuais e pequenas frustrações que o filho sofria ao explorar o ambiente, Lygia ressaltou que o percebia manifestando desagrado quando queria algo que não poderia pegar. No entanto, quando sofria uma queda durante a exploração do ambiente, ele ignorava e seguia com a brincadeira: "Muitas vezes ele ignora [as quedas], às vezes até eu 'meu Deus, ele vai chorar!', mas não! Ele continuou". Lygia ainda destacou que Érico, durante as brincadeiras, por vezes, necessitava retornar até ela para mostrar algum objeto e estabelecer interação. No que diz respeito à experiência do filho na creche, Lygia destacou que Érico permanecia cerca de oito horas e 30 minutos diariamente na creche, durante cinco dias na semana. Ela mencionou que percebia a creche como importante para o desenvolvimento do filho, principalmente, para sua socialização. Segundo Lygia, o convívio com adultos e crianças, assim como a imitação de outras crianças mais velhas, permitiu a Érico desenvolver novas habilidades:
Essa socialização ajuda bastante, o contato que eles têm eu acho bem importante... - Agora na hora das refeições, elas já estão dando os talheres assim, e vendo outras crianças, que são um pouquinho mais velhas que ele fazendo, ele faz também.

Lygia avaliou a creche de maneira positiva e ressaltou o quão bem o filho era cuidado nesse contexto: "Nossa, muito bom. A gente vê que elas [educadoras] têm muitos cuidados em todos os momentos, na horas das refeições, nas brincadeiras, então eu estou bem satisfeita". Ela também ressaltou a boa comunicação entre ela e as educadoras, no sentido de receber informações sobre o dia do filho: "Toda vez que eu chego, no fim do dia, que eu pego o Érico, elas sempre me passam o que ele fez durante o dia, como que foram as refeições, se ele deu uma choradinha".

A análise conjunta dos relatos indica a vivência da maternidade marcada por realização pessoal e pela identificação de Lygia com a própria mãe. Ao longo do período investigado, ela passou a perceber a sua competência como mãe a partir das conquistas do filho em seu processo de desenvolvimento. Os relatos associados ao filho indicam a percepção materna de vivência satisfatória do processo de separação-individuação, o que podia ser identificado através de comportamentos de Érico, como a observação de ambientes estranhos e posterior interação, e a maior independência no primeiro ano de vida. Por fim, com relação à entrada e experiência do filho na creche, os relatos destacaram a percepção da adaptação rápida de Érico e os ganhos em termos de desenvolvimento, como a socialização.

\section{Caso 3: Ruth (mãe) e Clarice (frequentava a creche)}

Separação-individuação e subfase de diferenciação ( $6^{\circ}$ mês). Com relação à experiência da maternidade, Ruth descreveu o ser mãe como algo "maravilhoso" e ressaltou que não imaginava a tamanha intensidade do amor recíproco entre mãe e filha. Da mesma forma, destacou que todo o investimento que dispensava a Clarice lhe trazia cansaço físico, mas que isso não se configurava como uma dificuldade na maternidade: 
"Estou tendo bastante trabalho. E, às vezes, exige um cansaço físico. Mas nenhuma dificuldade, nada que eu não consiga dar conta". Com relação ao desenvolvimento emocional da filha, Ruth destacou a boa relação estabelecida entre pai-mãe-bebê, e a sua percepção de que Clarice já diferenciava cada um dos genitores: " $E$ nós temos a impressão de que ela já sabe quem é . . quando ela fala 'papa' ela já sabe que é o papai e quando fala 'mama' que é a mamãe". Ela também ressaltou que a filha estava com maior firmeza corporal para sentar sozinha e que isso contribuiu, no seu entendimento, para uma maior interação com os objetos ao seu alcance. Com relação à adaptação da filha à creche, Ruth destacou que isso seguia o "curso normal das coisas", e não ressaltou sentimentos adversos a decisão de inserir a filha na educação infantil. A adaptação de Clarice foi considerada satisfatória e aconteceu durante o primeiro mês do bebê na creche. A adaptação se deu de forma gradativa e com horários reduzidos nas primeiras semanas. Ruth percebeu que a filha se sentia bem na creche, já que as educadoras eram bastante afetivas e atenciosas: "Eu gostei que ela se adaptou bem, que ela se sentiu bem lá, eu senti isso. Eu gostei das professoras que foram bem atenciosas".

Separação-individuação e subfase de exploração $\left(\mathbf{1 2}^{\circ}\right.$ mês $)$. Com relação à experiência da maternidade, Ruth definiu-se como uma mãe "dedicada" e "afetuosa", além de "orgulhosa" e "apaixonada" pela filha. Ela também destacou que se sentia segura com relação à maternidade, já que ainda não havia retomado a sua rotina intensa de estudos para poder dedicar mais tempo à filha: "Eu estou me sentindo bem, porque eu ainda não entrei numa rotina de estudo. Eu estudava muito antes de engravidar, e eu desliguei totalmente pra me dedicar a Clarice". Com relação ao desenvolvimento emocional da filha, ela destacou não perceber Clarice como mais independente, já que ela necessitava da presença dos pais durante as brincadeiras, e também devido ao fato de ainda ser amamentada. Apesar disso, Ruth ressaltou comportamentos mais independentes por parte dela: "Acho que pega alguma comidinha, toma água, isso mesmo, ela pega o copinho e toma". Ela também mencionou que percebia que a filha demonstrava prazer frente às tarefas que realizava de forma independente, além de sua crescente capacidade em explorar objetos e pessoas. Já com relação às eventuais e pequenas frustrações que Clarice sofria ao explorar o ambiente (ex. quedas, não poder pegar o que desejava), de maneira geral percebia que ela ignorava, mas protestava quando envolvia brinquedos: "No caso de caminhar, ela ignora. No caso de brincar, por exemplo, ela encaixou a caixinha do bico dela, ai não consegue mais abrir, ela fica braba, ela protesta". Ruth também percebia que a filha necessitava retornar até ela, entre uma brincadeira e outra, para estabelecer alguma interação. Já referente à experiência da filha na creche, Ruth destacou que Clarice permanecia cerca de nove horas diárias na creche, cinco dias por semana. Ela ressaltou habilidades adquiridas pela filha e as atribuiu à experiência na creche, como a maior facilidade para aprender. Ruth avaliou de forma positiva a escola que Clarice frequentava e destacou ser uma creche "nota dez". Ela mencionou características das educadoras, como serem "atenciosas", e de estrutura da creche, como número adequado entre adultos e crianças (um adulto para cada quatro crianças): "Eu acho que as professoras são muito atenciosas . . . que elas são em número adequado pra quantidade de crianças". Ruth ressaltou a boa comunicação com as educadoras sobre o dia de Clarice com elas. Para Ruth, tal aspecto mostrava que a filha era considerada em suas singularidades, e não como mais uma criança.

A análise conjunta dos relatos indica a vivência da maternidade marcada pela dedicação à filha e pelo amor recíproco entre as duas. Ao longo do período investigado, essa dedicação se manteve e a mãe postergou o seu retorno à rotina pessoal de estudos. Os relatos associados ao bebê denotavam a percepção materna de que o processo de separação-individuação transcorria como o esperado, marcado pelos comportamentos de Clarice, tais como diferenciar mãe e pai e demonstrar prazer frente às atividades que realizava de forma independente. Com relação à adaptação e experiência na creche, os relatos destacaram o bem-estar da mãe e da filha com relação à creche ao longo do período investigado. 


\section{Caso 4: Maria Clara (mãe) e Cecília (não frequentava a creche)}

Separação-individuação e subfase de diferenciação ( $6^{\circ}$ mês). Com relação à experiência da maternidade, Maria Clara definiu-se como "louca" por estar se dedicando exclusivamente aos cuidados da filha. Ela mencionou que tentou retomar o trabalho e deixar Cecília com o pai, mas não conseguiu ficar longe da filha, de modo que optou por parar de trabalhar: "Eu tentei voltar a trabalhar logo em seguida que ela largou o peito, mas dai ficar longe o dia todo não dá". Já com relação ao desenvolvimento emocional da filha, Maria Clara ressaltou a perceber como bastante decidida nas coisas que desejava. Também mencionou que Cecília não costumava estranhar pessoas desconhecidas e estabelecia boa interação: "Ela não é muito de estranhar assim, tu viu que contigo ela já foi bem tranquila". Maria Clara destacou que Cecília estava com maior firmeza para sentar, o que, segundo seu entendimento, possibilitou a ela estabelecer maior interação com os objetos ao redor.

Separação-individuação e subfase de exploração (12 mês). Com relação à experiência da maternidade, Maria Clara destacou que há cerca de um mês retornou ao trabalho, e tal aspecto foi percebido como positivo para a maternidade: "Agora que eu estou trabalhando, estou me sentindo ótima. Eu vejo que eu tenho mais paciência, tenho mais vontade de fazer as coisas do que quando eu só ficava em casa". Maria Clara trabalhava durante o período da manhã, de modo que Cecília passou a ser cuidada por uma tia-avó com a qual já convivia rotineiramente. Já referente ao desenvolvimento emocional da filha, ela destacou que Cecília estava caminhando e, com isso, a percebia desenvolvendo maior capacidade de interação com os brinquedos. Também ressaltou que, aos 12 meses, a filha a solicitava com maior frequência, o que a fazia percebê-la como mais dependente: "Ela está mais dependente. Ela me chama 24 horas por dia". No entanto, ela mencionou a capacidade da filha em realizar atividades sem precisar de ajuda e o prazer que ela demonstrava em obter tais conquistas. Maria Clara também mencionou a necessidade de Cecília vir até ela e manter contato físico entre uma brincadeira e outra, assim como a capacidade de acalmar-se facilmente frente às eventuais e pequenas frustrações que sofria ao explorar o ambiente: "Ela faz um drama, . . . depois de cinco segundos acaba".

A análise conjunta dos relatos indica $\mathrm{o}$ imperativo materno de ser a cuidadora exclusiva da filha nos primeiros meses de vida. Contudo, ao longo do período investigado Maria Clara percebeu a necessidade pessoal de retornar ao trabalho e permitir que outras pessoas assumissem os cuidados de Cecília. Já os relatos associados à filha denotavam a percepção materna de vivência satisfatória do processo de separação-individuação, demonstrado através de comportamentos como os de exploração do ambiente ao redor e os de retorno até a mãe a fim de reabastecer-se emocionalmente.

\section{Caso 5: Lya (mãe) e Fabrício (não frequentava a creche)}

Separação-individuação e subfase de diferenciação ( $6^{\circ}$ mês). Com relação à experiência da maternidade, Lya mencionou que se considerava uma boa mãe, já que era "cuidadosa", "tranquila" e "brincalhona". Ela também ressaltou que não imaginava que gostaria tanto de ficar em casa para cuidar do filho, e que estava com dificuldades para retornar ao trabalho: "Não pensei que eu ia gostar tanto de ficar em casa. . .. E agora pra mim está sendo mais difícil voltar a trabalhar". Com relação ao desenvolvimento emocional do filho, Lya ressaltou aspectos do desenvolvimento de Fabrício, como já sentar com apoio e, consequentemente, demonstrar maior interesse em explorar os objetos ao seu redor. Da mesma forma, destacou características dele que contribuíam, na sua percepção, para uma boa relação mãe-filho: "Ele é uma criança muito tranquila, bem risonho, muito brincalhão".

Separação-individuação e subfase de exploração ( $\mathbf{1 2}^{\mathbf{0}}$ mês). Com relação à experiência da maternidade, Lya se definiu como uma mãe cuidadosa, carinhosa e não permissiva. Ela destacou que estava "tranquila" em relação à maternidade e que contava com a ajuda familiar para poder, aos poucos, aumentar as horas de trabalho: "Eu estou bem tranquila. Agora estou 
trabalhando um pouco mais do que trabalhava antes, mas estou conseguindo ficar com ele, conciliar os horários, eu tenho bastante ajuda da família". Já referente ao desenvolvimento emocional do filho, ela percebia que Fabrício já demonstrava descontentamento nos momentos em que era contrariado, sendo que sinalizava o que o agradava e o desagradava. Ela também percebia que, aos 12 meses, o filho se comportava de forma mais independente, já que conseguia fazer determinadas atividades sem ajuda. No entanto, ela ressaltou que, apesar de mais independente, Fabrício necessitava retornar até ela, entre uma brincadeira e outra, para manter contato físico, antes de estruturar uma nova atividade de exploração. Já com relação às eventuais e pequenas frustrações que o filho sofria ao explorar o ambiente (ex. uma queda), Lya percebia que ele reagia inicialmente, mas se acalmava ao ser distraído para alguma outra atividade: "Mas é rápido, e ele se acalma. A gente distrai com alguma outra coisa, em geral se acalma rápido".

A análise conjunta dos relatos indica a satisfação materna frente aos cuidados do filho e dificuldades para retornar a rotina de trabalho. Ao longo do período investigado, Lya se permitiu aumentar as horas de trabalho, ao receber ajuda da família nos cuidados de Fabrício. Já os relatos associados ao filho denotavam aspectos que contribuíam para a percepção da boa relação mãe-bebê, como ele ser tranquilo e risonho. Também indicavam o seu entendimento da evolução satisfatória do processo de separação-individuação, através de comportamentos de Fabrício, como sinalizar o que o agradava ou não e as atitudes mais independentes.

\section{Caso 6: Adélia (mãe) e Caio (não frequentava a creche)}

Separação-individuação e subfase de diferenciação ( $6^{\circ}$ mês). Com relação à experiência da maternidade, Adélia destacou que, além de uma mãe "amorosa", ela era muito "ciumen$t a "$ com relação ao filho com outras pessoas: "Eu achava que ia ser uma mãe amorosa, agora eu estou vendo que sou uma mãe amorosa, mas ciumenta, né?". Ela também ressaltou que, por muito tempo, quis ser uma "super mãe", mas com o nascimento do filho passou a querer ser, simplesmente, "uma boa mãe". Com relação ao desenvolvimento emocional do filho, ela ressaltou que, aos 6 meses, percebia que Caio era uma criança mais calma do que nos meses anteriores, em que apresentou reações de choro intenso e prolongado ao longo do dia: "Então foi desgastante [o choro do filho nos meses iniciais], mas agora isso já passou, ele é mais calmo". Ela também ressaltou o fato de o filho já estar mais firme para sentar, o que permitia maior interação com o que estava ao seu alcance.

Separação-individuação e subfase de exploração (12 ${ }^{\circ}$ mês). Com relação à experiência da maternidade, Adélia destacou que se percebia como uma mãe "menos ciumenta" do que aos 6 meses do filho. Além disso, ela mencionou algumas dificuldades em relação à maternidade, principalmente no que se referia aos cuidados com a própria aparência:

Acho que eu estou descuidada de mim e estou num momento que eu não estou fazendo exercício, enfim, não faço mais as minhas unhas, não tenho mais essa regularidade. Mas agora está chegando um momento que eu acho que tenho que começar a retomar.

Com isso, ela ressaltou que, por vezes, se sentia "sobrecarregada", já que assumia muitas responsabilidades frente aos cuidados de Caio, apesar de o marido também assumir os cuidados do filho. Já referente ao desenvolvimento emocional do filho, Adélia destacou que ele iniciou o caminhar e, com isso, na sua percepção, adquiriu maior capacidade de exploração do ambiente. Da mesma forma, ele já manifestava mais intensamente o que o desagradava ao fazer "birrinha" e se "atirar no chão". Já frente às eventuais e pequenas frustrações que ocorriam no momento de exploração do ambiente (ex. uma queda), Adélia ressaltou perceber diferenças nas reações de Caio quando ele estava com ela ou com o pai. Ela destacou que, na sua presença, sentia que o filho tendia a chorar mais do que quando estava com o pai. Da mesma forma, ela ressaltou que percebia que ele apresentava maior capacidade de independência em relação ao pai, mas não em relação a ela. Adélia mencionou preocupação frente a esse comportamento, mas destacou 
acreditar que isso se referia a ela, e não necessariamente ao filho, o que sinalizava uma necessidade dela em se individuar de Caio: "Eu me sinto preocupada. Mas ai é o que eu te digo, acho que talvez, parta muito de mim. Eu que preciso agora começar a me separar dele, né?". No entanto, ela mencionou a capacidade do filho em realizar atividades sem precisar de ajuda e o prazer que ele demonstrava com tais conquistas. Quando questionada se Caio tinha necessidade de retornar até ela entre uma brincadeira e outra, Adélia respondeu afirmativamente e destacou que esse comportamento era frequente: "Ele vem e entrega uma coisa. Agora ele está muito de dar os bracinhos".

A análise conjunta dos relatos indica a vivência da maternidade marcada por ciúmes do filho e por redução de expectativas em relação ao papel materno. Contudo, ao final do período investigado, Adélia revelou-se menos ciumenta com relação ao filho e interessada em retomar os cuidados com a própria aparência. Já os relatos associados ao filho denotavam a percepção materna de vivência esperada do processo de separação-individuação no primeiro ano de vida. Caio, segundo relato materno, já identificava a mãe e o pai e tinha comportamentos diferentes na presença de um ou outro genitor. Tal aspecto possibilitou que Adélia ficasse mais consciente da necessidade de individuação entre mãe e filho.

\section{Discussão}

O objetivo do presente estudo foi investigar a vivência materna do processo de separação-individuação mãe-bebê no primeiro ano de vida. Em particular, buscou investigar, a partir do relato materno, as particularidades desse processo quando o bebê frequentava ou não a creche. Com relação ao bebê, se investigou a percepção materna referente à primeira individuação (Mahler et al., 1975/1977), que inicia em torno dos 4 meses e se consolida por volta dos 36 meses. Com relação à mãe, se investigou a percepção materna referente à terceira individuação (Colarusso, 1990), que ocorre na idade adulta e envolve a parentalidade. Por isso, ao longo do texto, fala-se em processo de separação-individuação mãe-bebê, por ocorrer de forma concomitante para a díade e ser influenciado mutuamente.

Os resultados do presente estudo revelaram que, independentemente dos bebês frequentarem ou não a creche, as mães relataram uma vivência positiva da maternidade aos 6 meses dos filhos, apesar das dificuldades experienciadas, como a rotina desgastante que cuidar de um bebê impõe. Os relatos maternos também sugerem que mães e filhos tinham estabelecido um forte vínculo de confiança básica (Erikson, 1968/1972), que pode ter contribuído para que os bebês adentrassem na subfase de diferenciação do processo de separação-individuação (Mahler et al., 1975/1977).

Alguns bebês passaram a frequentar a creche no $6^{\circ}$ mês de vida e as mães relataram que eles tiveram uma boa adaptação, pautada no respeito às características dos bebês e na relação afetiva com as educadoras. Como eles frequentavam a mesma creche, o período de adaptação foi organizado de maneira semelhante, com horários que aumentaram gradativamente ao longo dos dias e com a mãe presente na creche para atender eventuais solicitações. As mães destacaram o seu entendimento de que a adaptação ocorreu de forma rápida, durante o primeiro mês de frequência à instituição. É plausível supor que a dinâmica e estrutura da creche tenham facilitado a adaptação e, a presença de uma figura de referência para o bebê, pode ter contribuído para a confiança no novo ambiente. Isso pareceu permitir uma separação menos traumática em relação à mãe (Mahler et al., 1975/1977) e, de certa forma, possibilitou que as educadoras se tornassem, progressivamente, figuras afetivas para o bebê. Tal aspecto também foi ressaltado no estudo de Bossi et al. (2014) em que se constatou que, independentemente da idade de entrada na creche, a adaptação foi facilitada quando contava com a presença de uma figura de referência para a criança. Preferencialmente aquele genitor que se mostrava mais confiante quanto à adaptação do bebê e podia servir como suporte emocional para ele.

De certo modo, pode-se dizer que a entrada dos bebês na creche apresentou-se como um fator externo que impulsionou as mães e filhos a se separarem e se individuarem. De modo geral, 
não foram relatadas, pelas mães, dificuldades de adaptação à creche por parte do bebê. Por parte das mães também não ocorreram relatos que denotassem maiores sofrimentos frente às separações diárias. Contribuiu, para isto, a dinâmica e a qualidade do atendimento na creche, que foi ressaltada como muito boa nos relatos maternos.

Já para as mães que não inseriram os bebês na creche, algumas dificuldades foram relatadas. O processo de separação-individuação parece ter acompanhado o desenvolvimento do bebê e da própria mãe, de modo que o relato espontâneo das participantes sugeriu que elas não percebiam nos filhos e nem nelas mesmas a capacidade de se separarem um do outro, o que remete a dependência do bebê com relação à mãe/cuidador aos 6 meses de idade.

Apesar disso, independentemente de frequentarem ou não a creche, os relatos maternos referentes aos comportamentos dos seus bebês em situações do cotidiano, indicaram a percepção da vivência satisfatória do processo de separação-individuação. Contribui para isto o próprio desenvolvimento do bebê que passa a, progressivamente, manter-se mais alerta durante os períodos de vigília. Também, a aquisição das capacidades motoras em desenvolvimento, como o sentar, permitem que o bebê tenha uma visão mais ampla do ambiente, o que aumenta o seu interesse por novas descobertas (Mahler et al., 1975/1977). Essa experiência de desabrochamento permite à criança se direcionar para o interesse pelos objetos e avançar nas suas tentativas de separação-individuação.

Já aos 12 meses, os relatos das mães também apontaram para uma vivência positiva da maternidade, apesar de algumas dificuldades relacionadas às exigências constantes dos filhos que estavam se aventurando na exploração do ambiente. Com isso, destaca-se que os bebês apresentavam, de acordo com a percepção materna, comportamentos mais independentes em relação à mãe, mas isso não significava que eles não necessitavam de sua presença e ajuda para seguir em suas explorações. O mesmo foi descrito no estudo de Lopes et al. (2007) em que as mães ressaltaram os comportamentos mais ativos e independentes dos filhos, propiciado pelo desenvolvimento de suas habilidades motoras, bem como mencionaram a maior necessidade, por parte do bebê, de atenção, presença e proximidade física com a mãe. Tais características apontadas pelas participantes do presente estudo remetem a conquistas adquiridas durante a subfase de diferenciação, já mencionada acima. Assim que o bebê se individualiza o suficiente para reconhecer o rosto da mãe, e à medida que adquire confiança na provisão emocional materna, volta-se para a exploração do mundo externo com maior interesse, por confiar que sempre que precisar retornar até a mãe ela estará disponível para atendê-lo (Mahler et al., 1975/1977).

Os relatos das mães referentes aos seus filhos indicam a percepção materna de que eles vivenciavam a subfase de exploração do processo de separação-individuação da maneira esperada, independentemente de frequentarem ou não a creche. A capacidade de locomoção através do engatinhar, arrastar-se ou caminhar permitia ao bebê explorar um ambiente muito maior do que ele era capaz nos meses anteriores. Dessa forma, as participantes ressaltaram que os filhos demonstravam prazer frente às atividades e descobertas que realizavam sem a ajuda materna. No entanto, os momentos de aparente esquecimento da mãe eram momentâneos, de modo que os bebês necessitavam, de tempos em tempos, compartilhar suas conquistas, indo até as mães para manter contato físico antes de iniciar um novo comportamento de exploração. Mahler et al. (1975/1977) destacaram que tal comportamento estaria associado à necessidade de reabastecimento emocional por parte do bebê. Isso permite que ele confirme que a mãe continua pronta para atender suas necessidades, o que indica que ele pode explorar um mundo cada vez mais distante dela, sem perdê-la. Ainda, a capacidade dos bebês em tolerarem pequenas frustrações foi ressaltada pelas participantes, o que indicava a percepção materna de que eles estavam voltados, narcisicamente, para a conquista de suas capacidades motoras e de exploração. Mahler et al. (1975/1977) mencionaram que esse envolvimento narcísico permite ao bebê desenvolver a impermeabilidade à frustração, tornando-o mais tolerante a batidas, a quedas, ou a outras peque- 
nas frustrações que venha a sofrer, o que o impulsiona na exploração do ambiente ao redor.

Assim, apesar de três bebês deste estudo já estarem frequentando a creche há seis meses, enquanto os outros permaneciam sendo cuidados em casa, as mães não relataram muitas diferenças em relação ao desenvolvimento dos filhos, no que se refere à subfase de exploração. Isso sugere que o processo de separação-individuação pode ocorrer de forma aparentemente satisfatória, mesmo em contextos de creche, o que estende a hipótese inicial de Mahler et al. (1975/1977), que preconiza que o processo de separação-individuação ocorre na presença e disponibilidade emocional materna. Isso permite pensar que o cuidado oferecido na creche frequentada por esses bebês pode ter possibilitado o holding (Winnicott, 1965/1993) e o apoio necessários para que o processo de separação-individuação continuasse ocorrendo de maneira adequada, mesmo com o bebê estando distante da mãe.

Com relação às próprias mães, os resultados do presente estudo também apoiam o que Colarusso (1990) já havia mencionado e que foi ressaltado em outros estudos (Bellini, 2008; Diamond et al., 1996), ao destacar que, concomitantemente ao processo de separação-individuação do bebê, ocorre um processo correlato com a mãe. Ao perceberem o desenvolvimento e individuação dos filhos, as mães também passam a desejar se individuar deles, para retomarem uma vida estruturada para além dos cuidados dispensados aos filhos. O presente estudo corrobora, em certa medida, os resultados do trabalho de Bellini (2008) que mostrou que as mães manifestavam, ao longo dos dois primeiros anos do bebê, o desejo de retomarem um espaço psíquico mais individuado com relação ao filho. No estudo de Lopes et al. (2007), foi possível constatar algo semelhante, já que a medida que os bebês se mostravam mais independentes, as mães tendiam a incentivar esses momentos de afastamento do bebê.

No presente estudo, o processo de separação-individuação do bebê, associado à individuação da mãe, se apresentou com algumas particularidades entre as mães que tinham uma rotina intensa de trabalho diário e haviam colocado o filho na creche desde os 6 meses. Neste contexto, a individuação da mãe com relação ao seu bebê pareceu ocorrer influenciada por um agente externo, que foi o retorno ao trabalho e a entrada do bebê na creche. No entanto, o fato de os bebês terem frequentado a creche não pareceu exercer influência negativa no processo de separação-individuação. Aspectos relacionados ao vínculo afetivo mãe-bebê, bem como as características da creche e das educadoras, ressaltadas como muito afetivas pelas mães participantes, podem ter contribuído nesse sentido. $\mathrm{O}$ respeito às particularidades dos bebês, como mencionado pelas mães, pode ter permitido que as educadoras se tornassem uma referência para eles, o que de certo modo pode ter facilitado o seguimento do processo de separação-individuação. Da mesma forma, a presença de um vínculo afetivo mãe-filho tendeu a permitir, mesmo frente aos limites de tempo disponível de convívio com a mãe, o reabastecimento emocional necessário para que o bebê seguisse satisfatoriamente em seu desenvolvimento.

Por fim, cabe destacar algumas limitações teóricas e metodológicas do presente estudo. Por exemplo, as categorias investigadas sobre o processo de separação-individuação (Mahler et al., 1975/1977) foram acessadas a partir dos relatos maternos obtidos em entrevistas sujeitas as limitações inerentes a esse instrumento, particularmente quando se investiga conceitos com dimensões conscientes e inconscientes. Mahler et al. (1975/1977) igualmente trabalhou por meio de entrevistas com as mães, mas ela também recorreu a extensas horas de observações semanais da interação mãe-bebê. Assim, sugere-se que os próximos estudos sobre esta temática também possam se valer de observações. Além disso, sugere-se avançar nas demais subfases do processo de separação-individuação, não investigadas no presente estudo, com o objetivo de entender se a entrada na creche traria particularidades no momento da reaproximação ( $3^{\mathrm{a}}$ subfase; 17 a 24 meses) e consolidação da individuação ( $4^{\mathrm{a}}$ subfase; 25 a 36 meses).

Apesar dessas eventuais limitações, é importante ressaltar que o presente estudo traz con- 
tribuições para esta área, ao envolver dois contextos distintos para o desenvolvimento do bebê (creche ou não creche), investigados longitudinalmente no primeiro ano de vida. Isso amplia os achados da literatura, por considerar o contexto de creche permeando o processo de separação-individuação mãe-bebê, o que não foi ressaltado originalmente pela teoria de Mahler et al. (1975/1977). Os resultados não revelaram entraves a esse processo, associados à entrada ou não na creche, e isto sugere a importância do papel das educadoras como facilitadoras de um processo que aconteceria naturalmente a partir da relação mãe-bebê e que, atualmente, é cada vez mais permeado pela presença da creche. Dessa forma, é importante que se possa pensar em intervenções voltadas para as educadoras, a fim de sensibilizá-las para os aspectos emocionais da relação mãe-bebê-educadora, e que possam contribuir para o processo de separação-individuação do bebê e da própria mãe, que deixa seu filho aos cuidados da creche. Além disso, também é possível pensar em intervenções breves e focadas para a díade mãe-bebê, tanto nos casos de bebês que frequentam ou não a creche, a fim de acolher as angústias maternas frente às implicações psicológicas do processo de separação-individuação, tanto para o bebê como para si, e para a relação mãe-bebê.

\section{Referências}

Aslan, S. (2013). The prediction of separation-individuation in Turkish late adolescents through five factor personality dimensions. Eurasian Journal of Educational Research, 51, 7-20.

Bellini, L. (2008). A vivência materna do processo de separação-individuação mãe-bebê no primeiro ano de vida até a entrada na educação infantil (Dissertação de mestrado, Instituto de Psicologia, Universidade Federal do Rio Grande do Sul, Porto Alegre, RS, Brasil).

Bossi, T. J., Soares, E., Lopes, R. C. S., \& Piccinini, C. A. (2014). Adaptação à creche e o processo de separação-individuação: Reações dos bebês e sentimentos parentais. Psico PUCRS, 45(2), 250-260. doi: http://dx.doi.org/10.15448/19808623.2014.2.16283
Colarusso, C. A. (1990). The third individuation: The effect of biological parenthood on separation-individuation processes in adulthood. Psychoanalytic Study of the Child, 45, 179-194.

Diamond, D., Heinicke, C., \& Mintz, J. (1996). Separation-individuation as a family transactional process in the transition to parenthood. Infant Mental Health Journal, 17(1), 24-42. doi: http://doi.org/10.1002/ (SICI) 1097-0355(199621)17:1<24::AIDIMHJ3>3.0.CO;2-1

Erikson, E. (1972). Identidade, juventude e crise. Rio de Janeiro, RJ: Zahar. (Original publicado em 1968)

Harms, T., Cryer, D., \& Clifford, R. (2003). Infant/ toddler Environment Rating Scale Revised Edition. New York: Teachers College Press.

Instituto Nacional de Estudos e Pesquisas Educacionais Anísio Teixeira. (2014). Censo Escolar da Educação Básica 2013 - Resumo Técnico. Brasília, DF: Autor. Recuperado em http://download.inep.gov.br/educacao_basica/censo_escolar/ resumos_tecnicos/resumo_tecnico_censo_educacao_basica_2013.pdf

Kins, E., Soenens, B., \& Beyers, W. (2011). "Why do they have to grow up so fast?" Parental separation anxiety and emerging adults' pathology of separation-individuation. Journal of Clinical Psychology, 67(7), 647-664. doi: 10.1002/ jclp.20786

Kins, E., Soenens, B., \& Beyers, W. (2012). Parental psychological control and dysfunctional separation-individuation: A tale of two different dynamics. Journal of Adolescence, 35(5), 10991109. doi: http://dx.doi.org/10.1016/j.adolescence.2012.02.017

Koepke, S., \& Denissen, J. J. A. (2012). Dynamics of identity development and separation-individuation in parent-child relationships during adolescence and emerging adulthood - A conceptual integration. Developmental Review, 32, 67-88. doi: 10.1016/j.dr.2012.01.001

Laville, C., \& Dionne, J. (1999). A construção do saber: Manual de metodologia da pesquisa em ciências humanas. Porto Alegre, RS: Artmed.

Lopes, R. de C. S., Oliveira, D. S., Vivian, A. G., Bohmgahren, L. M. C., Piccinini, C. A., \& Tudge, J. (2007). Sentimentos maternos frente ao desenvolvimento da criança aos 12 meses: Conviven- 
do com as novas aquisições infantis. Psicologia: Teoria e Pesquisa, 23(1), 5-16.

Mahler, M. (1982). O processo de separação-individuação. Porto Alegre, RS: Artes Médicas. (Original publicado em 1979)

Mahler, M., Pine, F., \& Bergman, A. (1977). O nascimento psicológico da criança. Rio de Janeiro, RJ: Zahar. (Original publicado em 1975)

Meeus, W., Iedema, J., Maassen, G., \& Engels, R. (2005). Separation-individuation revisited: On the interplay of parent-adolescent relations, identity and emotional adjustment in adolescence. Journal of Adolescence, 28(1), 89-106. doi: http://dx.doi.org/10.1016/j.adolescence.2004.07.003

Núcleo de Infância e Família/Projeto CRESCI. (2011a). Ficha de dados demográficos da família. Material não publicado. Universidade Federal do Rio Grande do Sul, Porto Alegre, RS, Brasil.

Núcleo de Infância e Família/Projeto CRESCI. (2011b). Entrevista sobre a experiência da maternidade. Material não publicado. Universidade Federal do Rio Grande do Sul, Porto Alegre, RS, Brasil.

Núcleo de Infância e Família/Projeto CRESCI. (2011c). Entrevista sobre os momentos de separações mãe-bebê - $6^{o}$ mês. Material não publicado. Universidade Federal do Rio Grande do Sul, Porto Alegre, RS, Brasil.

Núcleo de Infância e Família/Projeto CRESCI. (2011d). Entrevista sobre a adaptação do bebê à creche-Versão mãe. Material não publicado. Universidade Federal do Rio Grande do Sul, Porto Alegre, RS, Brasil.
Núcleo de Infância e Família/Projeto CRESCI. (2011e). Entrevista sobre a experiência da maternidade $-12^{\circ}$. Mês. Material não publicado. Universidade Federal do Rio Grande do Sul, Porto Alegre, RS, Brasil.

Núcleo de Infância e Família/Projeto CRESCI. (2011f). Entrevista sobre os momentos de separações mãe-bebê- $12^{\circ}$ mês. Material não publicado. Universidade Federal do Rio Grande do Sul, Porto Alegre, RS, Brasil.

Observatório do Plano Nacional da Educação. (2016). Educação infantil. Recuperado em http://www. observatoriodopne.org.br/metas-pne/1-educacao-infantil

Piccinini, C. A., Becker, S. M. S., Martins, G. D. F., Lopes, R. C. S., \& Sperb, T. M. (2011). O impacto da creche no desenvolvimento socioemocional e cognitivo infantil: Estudo longitudinal do sexto mês de vida do bebê ao final dos anos pré-escolares - CRESCI. Projeto de pesquisa não publicado. Universidade Federal do Rio Grande do Sul, Porto Alegre, RS, Brasil.

Stake, R. E. (2006). Multiple Case Study Analysis. New York: The Guilford Press.

Winnicott, D. W. (1993). A família e o desenvolvimento individual. São Paulo, SP: Martins Fontes. (Original publicado em 1965)

Recebido: 04/04/2016

$1^{a}$ revisão: $13 / 01 / 2017$

$2^{a}$ revisão: $23 / 10 / 2017$

Aceite final: 17/12/2017

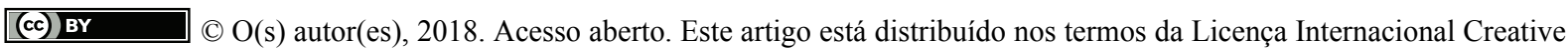
Commons Atribuição 4.0 (http://creativecommons.org/licenses/by/4.0/), que permite o uso, distribuição e reprodução sem restrições em qualquer meio, desde que você dê crédito apropriado ao(s) autor(es) original(ais) e à fonte, fornecer um link para a licença Creative Commons e indicar se as alterações foram feitas. 